\title{
Influence of the menstrual cycle on the incidence of nausea and vomiting after laparoscopic gynecological surgery: a pilot study.
}

\author{
Tatjana Simurina \\ University of Zadar, General Hospital Zadar
}

Boris Mraovic

Thomas Jefferson University

Neven Skitarelić

University of Zadar

Tatjana Andabaka

University of Zadar, General Hospital Zadar

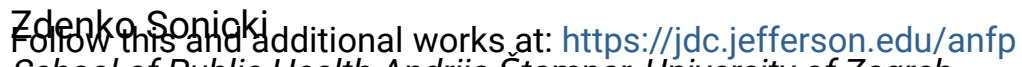

srhool of Public Health Andrija Stampar, University of Zagreb

Part of the Anesthesiology Commons, and the Cardiology Commons

\section{Let us know how access to this document benefits you}

\section{Recommended Citation}

Simurina, Tatjana; Mraovic, Boris; Skitarelić, Neven; Andabaka, Tatjana; and Sonicki, Zdenko, "Influence of the menstrual cycle on the incidence of nausea and vomiting after laparoscopic gynecological surgery: a pilot study." (2012). Department of Anesthesiology Faculty Papers. Paper 18.

https://jdc.jefferson.edu/anfp/18

This Article is brought to you for free and open access by the Jefferson Digital Commons. The Jefferson Digital Commons is a service of Thomas Jefferson University's Center for Teaching and Learning (CTL). The Commons is a showcase for Jefferson books and journals, peer-reviewed scholarly publications, unique historical collections from the University archives, and teaching tools. The Jefferson Digital Commons allows researchers and interested readers anywhere in the world to learn about and keep up to date with Jefferson scholarship. This article has been accepted for inclusion in Department of Anesthesiology Faculty Papers by an authorized administrator of the Jefferson Digital Commons. For more information, please contact: JeffersonDigitalCommons@jefferson.edu. 


\section{As submitted to: \\ Journal of Clinical Anesthesia}

And later published as:

Influence of the menstrual cycle on the incidence of nausea and vomiting after laparoscopic gynecological surgery:
A pilot study

\section{Volume 24, Issue 3, May 2012, Pages 185-192 \\ DOI: 10.1016/j.jclinane.2011.07.011}

Short title: Menstrual cycle and PONV

Tatjana Šimurina, $\mathrm{MD}, \mathrm{PhD}^{1 *}$, Boris Mraovic, $\mathrm{MD}^{2}$, Neven Skitarelić, $\mathrm{MD}, \mathrm{PhD}^{3}$, Tatjana Andabaka, $\mathrm{MD}^{1}$, Zdenko Sonicki, $\mathrm{MD}, \mathrm{PhD}^{4}$

${ }^{1}$ Department of Anesthesiology and Intensive Care Unit, General Hospital, Zadar, Croatia

${ }^{2}$ Associate Professor, Department of Anesthesiology, Thomas Jefferson University, Philadelphia, PA, USA

${ }^{3}$ Professor, Medical High School, University of Zadar, Department of ENT, General Hospital, Zadar, Croatia 
${ }^{4}$ Assistant Professor, Department of Medical Statistics, Epidemiology and Medical Informatics, School of Public Health “Andrija Štampar”, University of Zagreb, Zagreb, Croatia

This work was carried out at the Department of Anesthesiology and Intensive Care Unit, General Hospital, Zadar, Croatia.

Presented at ESA meeting, Milan, Italy, June 2009 and CAS meeting, Montréal, Canada, June 2010 .

Supported in part by the Croatian Ministry of Science, Education and Sport; research project "Predictive Models in Health Care" No. 108-0982560-0257.

*Corresponding author: General Hospital Zadar, Bože Peričića 5, 23000 Zadar, Croatia, Phone: +385 23 315677, Fax: +385 23 311969, Email: tatjana_simurina@yahoo.com Word Count: 2747

Keywords: Gynecologic surgical procedures; laparoscopy; menstrual cycle: follicular phase and a luteal phase; postoperative complications: nausea and vomiting. 


\section{Abstract}

Study objective: To investigate whether the phase of menstrual cycle has influence on the incidence of PONV in women undergoing general anesthesia for elective laparoscopic gynecological surgery.

Design: A prospective, observational, blinded study.

Settings: General hospital, postanesthesia care unit (PACU) and gynecologic floor room.

Patients: 111 ASA physical status I and II women, aged 18 to 53 years.

Interventions: Patients were classified into three groups according to the phase of menstrual cycle at the time of anesthesia: F1 - follicular phase (menstrual days 1-8) $(n=34), O 2$ - ovulatory phase $(9-15)(n=40)$ and L3 - luteal phase (16 to end of cycle) $(n=37)$. Anesthetic, postoperative pain management and antiemetic regimen were standardized.

Measurements: Incidences of nausea, vomiting or both were assessed for early (0-2h) and late PONV (2-24h) along with the use of rescue antiemetic, severity of nausea and pain. Main results: In the follicular $(n=34)$, ovulatory $(n=40)$ and luteal phase $(n=37)$ groups the incidences of PONV over 24 hours were $35 \%, 38 \%$ and $14 \%(\mathrm{p}=0.04)$, respectively. This was due to differences in the early postoperative period where the incidences were $21 \%, 25 \%$, and $3 \%,(\mathrm{p}=0.02)$ as incidences were similar in the late period $(15 \%, 20 \%$ and $14 \%, \mathrm{p}=0.71$ ), respectively. Nausea scores, rescue antiemetic usage, pain scores and opioid consumption were similar in the groups.

Conclusion: Patients in the luteal phase of their menstrual cycle might have a decreased risk of PONV after laparoscopic gynecological surgery in the early postoperative period. 


\section{Introduction}

Female sex is a known independent predictor for postoperative nausea and vomiting (PONV) [1]. Women have 2 to 4 times higher PONV risk than men [2]. The increased risk is not seen in children before puberty [3] and in postmenopausal women over 50 years of age the incidence is decreasing but it is still higher than in men [4]. This suggests a role of sex hormones in the etiology. Indeed, estrogen levels may influence PONV after general anesthesia for gynecological laparoscopy [5]. Furthermore, menstrual cycle irregularity often corresponds to hormonal disturbances and also increases the risk of PONV [6].

Sex hormone variations during menstrual cycles and their influence on PONV are not well studied. Recent guidelines of the Society for Ambulatory Anesthesia for the management of PONV did not identify menstrual phase as an independent predictor for PONV [2]. A meta-analysis of 12 studies in different surgeries suggested no significant influence of the day or phase of the menstrual cycle on PONV [7], but gynecological laparoscopic surgery was not analyzed separately. Gynecologic laparoscopic surgery may have an increased incidence of PONV compared to the other surgeries [2], suggesting that additional predictors and/or mechanisms of PONV may be involved. Indeed, a large multicentre study (IMPACT study) reported that only hysterectomy had significantly increased odds ratio for PONV (1.94; CI 1.43, 2.63; P<0.001) compared with all other surgeries [8].

Published studies on the influence of the menstrual cycle on PONV in gynecological laparoscopy reported controversial results. While the follicular phase of the menstrual 
cycle increased the risk for PONV in some studies [9-11], the luteal phase increased the risk in another [12]. Moreover both phases, follicular and luteal increased the risk in one study [13] but not in a multicentre study [14] or a factorial trial of six interventions for the prevention of PONV (IMPACT study) [8] (Table 1).

We designed a prospective, observational study that was controlled for known independent PONV predictors to determine whether the menstrual cycle phase influenced on PONV in fertile women with regular cycles undergoing general anesthesia for elective laparoscopic gynecological surgery. 


\section{Materials and methods}

After approval by the Ethics Committee of the General Hospital, Zadar, Croatia, and written informed consent, 111 adult fertile women receiving general anesthesia for elective laparoscopic gynecologic surgery were included in the study. The study was conducted from April 2007 to May 2009 at the General Hospital, Zadar. Inclusion criteria were ASA physical status (ASA-PS) I and II and a regular menstrual cycle. We defined a regular cycle as lasting 23 days to 35 days with no variations in length from cycle to cycle more than two days. The day of the cycle on which surgery took place was calculated from the first day of the last menstrual bleeding.

Exclusion criteria were pregnancy; those receiving hormones and medications that affected ovulation during the 6 weeks before surgery; those who had given birth or who were less than two months from termination of pregnancy; breast-feeding; obesity (BMI $\left.>30 \mathrm{~kg} / \mathrm{m}^{2}\right)$; known hypersensitivity to drugs used in the study protocol; use of antiemetics, psychotropic drugs and steroids within 72 hours before the surgery; nausea and vomiting prior the surgery; history of abdominal laparatomies; comorbidities that may have an influence on PONV like diseases which impaired gastric motility (diabetes mellitus, chronic cholecystitis, gastric and intestinal disease, neuromuscular disorders, neuropathies, liver dysfunction), vestibular disease, history of migraine headache, central nervous system injury, renal impairment, alcoholism and opioid addiction. Patients were excluded from the study if they developed conditions that influence incidence of PONV such as intraoperative drug allergy, severe intraoperative hypotension, perioperative 
hypoxia, excessive blood loss, difficult intubation, laparoscopic procedure converted to laparotomy or if serious postoperative complications developed.

Patients were classified into the three groups on the basis of the phase of the menstrual cycle at the time of surgery: Group F1- follicular phase (days 1- 8); Group O2-ovulatory phase (days 9-15); and Group L3-luteal phase (days 16 to end of cycle). Patients fasted at least 6 hours but allowed to drink clear fluids up to three hours before surgery. All patients received $7.5 \mathrm{mg}$ of midazolam orally 1 hour before surgery and no prophylactic antiemetics, which was the standard of care in our hospital.

Standard monitoring was used including electrocardiography, noninvasive blood pressure, pulse oximetry and capnography. Anesthesia was induced with thiopental 5 $\mathrm{mg} / \mathrm{kg}$ and fentanyl 1-2 $\mu \mathrm{g} / \mathrm{kg}$. Patients were manually ventilated via face mask with oxygen for three minutes before endotracheal intubation facilitated by intravenous (IV) vecuronium $0.1 \mathrm{mg} / \mathrm{kg}$. Anesthesia was maintained with sevoflurane $1.5-2 \%$ concentration (end tidal concentration one minimum alveolar concentration [MAC]) in a gas mixture consisting of $40 \%$ oxygen in air. Supplemental bolus doses of fentanyl IV $(1 \mu \mathrm{g} / \mathrm{kg})$ to keep heart rate and blood pressure within $20 \%$ of baseline values were given, as well as, additional vecuronium to maintain a one or two twitches on the train-of-four monitor. All patients received $10 \mathrm{ml} / \mathrm{kg} / \mathrm{h}$ of crystalloids during surgery. A nasogastric tube was not placed. Patients were mechanically ventilated to keep normocapnia (end tidal $\mathrm{CO}_{2} 36-38 \mathrm{mmHg}$ ). All laparoscopies were performed with intraabdominal $\mathrm{CO}_{2}$ insufflation. Sevoflurane was discontinued at the start of skin closure. At the end of surgery, neuromuscular blockade was antagonized with neostigmine $2.5 \mathrm{mg}$ and atropine $1 \mathrm{mg}$ IV. Postoperatively, patients received $5 \mathrm{ml} / \mathrm{kg} / \mathrm{h}$ of crystalloids and were allowed to 
drink after three hours, if tolerated. All patients stayed in the hospital for at least 24 hours.

The incidence of postoperative nausea (PON), vomiting (POV) and the use of rescue antiemetic were collected at 2 and 24 hours after surgery. Severity of PON and pain were evaluated using a $100 \mathrm{~mm}$ visual analog scale (VAS) at the same time points (VAS $0=$ no pain/nausea, $100=$ maximal pain/nausea). On the day of surgery, anesthesiologist who collected patients' data also instructed each patient in VAS scoring. A VAS score for PON was measured for each episode, but the highest score was used for the statistical analysis. Patients were considered to have had PONV if they experienced at least one episode of nausea, vomiting or retching or any combination of these during the first 24 postoperative hours. POV was defined as at least one episode of vomiting or retching that occurred within 24 postoperative hours. PONV was defined as early (within first two hours in postoperative recovery area) or late (within two to 24 postoperative hours on the ward). Three clinical nurses who were specifically trained for the study and were blinded to study group allocation, collected the data. Rescue antiemetic (metoclopramide $0.4 \mathrm{mg}$ $/ \mathrm{kg}$ IV) was given to patients who experienced two or more episodes of vomiting and /or retching within a period of $30 \mathrm{~min}$, any nausea lasting more than $15 \mathrm{~min}$ or nausea VAS score $50 \mathrm{~mm}$ or greater, or when they requested treatment. Pain VAS score and total amount of postoperative opioids were recorded at $2 \mathrm{~h}$ and 24 hours after surgery. Intramuscular (IM) diclofenac $75 \mathrm{mg}$ was given immediately after surgery and, if needed, 12 hours later. For severe pain (VAS >40 mm) meperidine up to $100 \mathrm{mg}$ IV was given, then repeated 4 hours later if needed. The incidence of early and late PONV was the 
primary endpoint of the study and the use of rescue antiemetic, severity of nausea and pain were the secondary endpoints.

Sample size calculation was based on the incidence of PONV that was recorded in our preliminary study: $29 \%$ in the follicular phase (days 1-8), $40 \%$ in the ovulatory phase (days 9-15) and $15 \%$ in the luteal phase group (days 16 to end of menstrual cycle) [15]. All patients from the preliminary study were included in this study. Power analysis, using PASS (Power Analysis and Sample Size) 2008, version 8.0.5 software (NCSS, Kaysville, UT, USA) showed that a total of 108 patients, or 36 per group, was sufficient to demonstrate a $30 \%$ difference in PONV incidence, with effect size $\mathrm{w}=0.3$ and $80 \%$ power at a 2 -sided $\alpha$ level of 0.05 . A total of 111 patients were enrolled in the study so as to allow for a 3\% dropout rate. Data were analyzed using statistical program SAS 8.2 (SAS Institute, Chicago, IL, USA). Quantitative values were analyzed using the Kruskal-Wallis and Mann Whitney tests and categorical data by Pearson Chi-Square analysis and Fisher's Exact test. Risk scores for PONV were calculated according to Apfel et al. [1]. A $\mathrm{P}$ value $<0.05$ was considered statistically significant. 


\section{Results}

All 111 patients successfully completed the study (Figure 1). Data from all patients were included in the statistical analysis. According to the phase of menstrual cycle at the time of surgery, 34 patients were assigned to the follicular group (Group F1), 40 patients to the ovulatory group (Group O2) and 37 to the luteal phase group (Group L3). Patients' demographic and intraoperative data did not differ among the three groups except in duration of anesthesia between Groups L3 and O2 (Table 2). There were no differences with respect to calculated PONV risk score $(\mathrm{P}=0.29)$ (Table 2).

There was an overall statistically significant difference for PONV at 24 hours. This finding was due to differences in the early postoperative period $(0-2 \mathrm{~h})$ where the incidences were lowest in Group L3 (Table 3). There was no difference in late PONV (2$24 \mathrm{hrs}$ ), nausea at 24 hours or late nausea and VAS scores for nausea (Table 3). Although the incidence of postoperative vomiting (POV) was lowest in Group L3 in early POV and at 24 hours, the difference did not reach statistical significance (Table 3). There was no difference in the incidence of severe nausea: Group F1=3 (9\%), Group O2=5 (13\%) and Group L3=2 (5\%) or severe POV: Group F1=1 (3\%), Group O2=1 (3\%) and Group L3=1 (3\%). Also, there was no difference in the number of patients who received metoclopramide: Group F1=5 (15\%), Group O2=5 (13\%) and Group L3=2 (5\%). The VAS pain scores at $2 \mathrm{~h}$ and 24 hours after surgery were similar among the groups, as well as, total amount of intraoperative opioids and postoperative pain medications given (Table 4). No adverse events among any patients were noted during the study period. 


\section{Discussion}

This pilot study suggests that the incidence of PONV in the early postoperative period after gynecologic laparoscopic surgery is decreased in the luteal phase of the menstrual cycle compared with the follicular and the ovulatory phases of the cycle. In the early postoperative period, the incidence of nausea but not of vomiting was decreased during the luteal phase. The results of this study were similar to studies that suggested that the early phase of the cycle increases risk of PONV [9-11], but differed with those that determined that the luteal phase was a predictor of PONV [12, 13] and likewise to those studies that found no influence of the cycle on PONV [14, 16, 17]. Small, single-center studies may not have enough power to answer the question, but a subsequent metaanalysis may be helpful. Indeed, meta-analysis by Eberhart et al suggested that menstrual cycle phase had no impact on PONV [7]. Their study found no differences in incidence of PONV among the different phases of the cycle but showed the highest incidence of PONV on postoperative day (POD) 5 and the lowest incidence from POD 16 to 21, a finding that was similar to our own [7].

One of the major issues in studying the influence of menstrual cycle is inconsistent definitions of menstrual phases and variation of menstrual cycle from woman to woman and from cycle to cycle. Clinical prediction of the ovulatory phase is uncertain. On average, ovulation is calculated 14 days prior to the next menstruation but it may vary from 10 to 16 days or more. Moreover, menstrual cycle irregularity may contribute to the increased risk of PONV [6]. For this reason we included in our study only those patients with the regular cycles of average duration (28 \pm 1.3 days). During a regular menstrual 
cycle, there are two surges in estrogen levels, in the ovulation and the luteal phase, and one progesterone surge, which occurs during the luteal phase. We divided the menstrual cycle into three phases to evaluate all three hormonal states during the cycle: follicular phase with both, estrogen and progesterone low, ovulatory phase with estrogen high, and luteal phase with both estrogen and progesterone high. We believe that this is a more physiologic approach than studies with two groups only (menstrual vs non-menstrual) or 5 groups (premenstrual, menstrual, follicular, periovulatory, luteal).

The increased incidence of PONV in women, which starts with the fertile period, as well as, during pregnancy, suggests the involvement of sex hormones in the PONV mechanism [18]. It is unclear which are the responsible hormones. Estradiol, not estriol or progesterone, increases vomiting during pregnancy [19]. Estrogen also may be involved in the increased incidence of PONV [5].

The studies of PONV have not measured sex hormone levels perioperatively. This fact may explain the controversial results reported on the influence of menstrual cycle on PONV after gynecological laparoscopy (Table 1). Only three abstracts and one paper have attempted to correlate hormonal levels, with completely different results $[5,16,17,20]$. One report suggested that higher estradiol levels increased risks for PONV [5]; another showed that the lower levels were associated with PONV in the perimenstrual phase but not across the cycle [20]; a third report stated that PONV patients had lower mean estradiol levels regardless of cycle [16], and finally, the paper (in Korean) that suggested that estradiol had no influence on PONV at all [17]. One measurement preoperatively may not be sufficient to confirm the phase of the cycle. The change in hormone levels may be more important, as well as the relative ratios among 
estrogen, estradiol, and progesterone. A study with serial hormone measurement may provide the definitive answer.

There are several limitations to this study. Although, duration of anesthesia was greater in Group L3 (luteal phase) than Group O2 (ovulatory phase), we do not think that this influenced our conclusions since the longer duration of anesthesia is associated with increase incidence of PONV not lower. We did not use PONV prophylaxis in this study, as it was the hospital's policy not to use pharmacological prophylaxis. The results of this study may not be reproducible in the patients receiving PONV prophylaxis. Although, we enrolled patients with a regular cycle, the ovulation date was estimated. The possibility of nonovulatory cycles also may have biased the results. Hormonal measurements and/or ultrasound examinations to confirm ovulation and phase of cycle were not performed. The high cost of the tests and repeat hormonal measurements in relatively young, healthy and ambulatory patients before surgery may render a study difficult to conduct. The other option, in clarifying the influence of the menstrual cycle on PONV, is to schedule the date of the surgery according to the cycle phases. For example, patients with a regular cycle may be prospectively randomized to have surgery either few days after menstruation (follicular phase) or two to three weeks after menstruation (luteal phase). Scheduling a gynecologic surgery in the luteal phase of the menstrual cycle may not be popular in some surgeons who like to avoid manipulations around the yellow body (corpus luteum) during gynecological surgery. Furthermore, the risk of perioperative bleeding may be higher in the luteal phase than the follicular phase of the cycle [21]. On the other hand, perioperative blood loss was increased during the perimenstrual phase compared with the periovulatory phase in breast reduction surgery [22]. The effect of 
menstrual phases on perioperative bleeding in gynecologic laparoscopic surgery is not known. However, in this study perioperative blood loss was minimal in all surgeries. In conclusion, in the luteal phase of the menstrual cycle after gynecologic laparoscopic surgery, the incidence of PONV may be decreased in the early postoperative period.

\section{Author Disclosure:}

Drs. Tatjana Šimurina, Boris Mraović, Neven Skitarelić, Tatjana Andabaka and Zdenko Sonicki have no conflicts of interest or financial ties to disclose. 


\section{References}

[1] Apfel CC, Läärä E, Koivuranta M, Greim CA, Roewer N. A simplified risk score for predicting postoperative nausea and vomiting. Conclusions from cross-validations between two centers. Anesthesiology 1999;91:693-700.

[2] Gan TJ, Meyer TA, Apfel CC, et al. Society of ambulatory anesthesia guidelines for the management of postoperative nausea and vomiting. Anesth Analg 2007;105:1615-28. [3] Gan TJ, Meyer T, Apfel CC, et al. Consensus guidelines for managing postoperative nausea and vomiting. Anesth Analg 2003;97:62-71.

[4] Moller DH, Glass PS. Should a patient's gender alter the anesthetic plan? Curr Opin Anaesthesiol 2003;16:379-83.

[5] Lindblad T, Forrest JB, Buckley DN, Beattie WS. Anaesthesia decreases a hormone mediated threshold for nausea and vomiting. Anesth Analg 1990;70:S242.

[6] Harmon D, O'Connor P, Gleasa O, Gardiner J. Menstrual cycle irregularity and the incidence of nausea and vomiting after laparoscopy. Anaesthesia 2000;55:1164-7.

[7] Eberhart LHJ, Morin AM, Georgieff M. Menstruationszyklus in der postoperativen Phase. Der Einfluss auf die Inzidenz von Übelkeit und Erbrechen. Anaesthesist 2000;49:532-5.

[8] Apfel CC, Korttila K, Abdalla M, et al. A factorial trial of six interventions for the prevention of postoperative nausea and vomiting. N Engl J Med 2004;350:2441-51.

[9] Beattie WS, Lindblad T, Buckley DN, Forrest JB. Menstruation increases the risk of nausea and vomiting after laparoscopy. Anesthesiology 1993;78:272-6. 
[10] Beattie WS, Lindbland T, Buckley DN, Forrest JB. The incidence of postoperative nausea and vomiting in women undergoing laparoscopy is influenced by the day of menstrual cycle. Can J Anaesth 1991;38:298-302.

[11] Möllhoff Th, Burgard G, Prien Th. Übelkeit and Erbrechen nach gynäkologischen laparoskopien. Anästhesiol Intensivmed Notfallmed Schmerzther 1995;30:23-7.

[12] Honkavaara P, Lehtinen AM, Hovorka J, Korttila K. Nausea and vomiting after gynaecological laparoscopy depends upon the phase of the menstrual cycle. Can J Anaesth 1991;38:876-9.

[13] Sener EB, Kocamanoglu S, Cetinkaya MB, Ustun E, Bildik E, Tur A. Effects of menstrual cycle on postoperative analgesic requirements, agitation, incidence of nausea and vomiting after gynecologic laparoscopy. Gynecol Obstet Invest 2005;59:49-53. [14] Gratz I, Allen E, Afshar M, Joslyn AF, Buxbaum J, Prilliman B. The effects of menstrual cycle on the incidence of emesis and efficacy of ondansetron. Anesth Analg 1996;83:565-9.

[15] Šimurina T, Mraović B, Sonicki Z, Sulen N, Dukić B. Does Menstrual Phase Influence Nausea and Vomiting after Gynecologic Laparoscopic Surgery? Anesthesiology 2007;107:A1016.

[16] Green G. Levels of estradiol but not phase of menstrual cycle influences the incidence of post-operative nausea and vomiting among fertile women. Acta Anaesthesiol Scand 1997;41(suppl 110):173,PD42.

[17] Lee JW, Kim SK, Kim DC, Han YJ, Ko SH. The effects of female hormones on postoperative nausea and vomiting. Korean J Anesthesiol 2008;54:58-62.

[18] Gan TJ. Risk factors for postoperative nausea and vomiting. Anesth Analg 
2006;102:1884-98.

[19] Lagiou P, Tamimi R, Mucci LA, Trichopoulos D, Adami HO, Hsieh CC. Nausea and vomiting in pregnancy in relation to prolactin, estrogens, and progesterone: a prospective study. Obstet Gynecol 2003;101:639-44.

[20] Harmon D, Connor PO, Lennon M, Hamilton V, Moran C, Gardiner J. The effects of the menstrual cycle and oestradiol concentration on postoperative nausea and vomiting. Eur J Anaesthesiol 2000;17(suppl 19):13.

[21] Paraskevaidis E, Davidson EJ, Koliopoulos G, Alamanos Y, Lolis E, Martin-Hirsch P. Bleeding after loop electrosurgical excision procedure performed in either the follicular or luteal phase of the menstrual cycle: a randomized trial. Obstet Gynecol 2002;99:997-1000.

[22] Sariguney Y, Demirtas Y, Findikcioglu F, et al. Proper timing of breast reduction during the menstrual cycle. Ann Plast Surg 2004;53:528-31. 


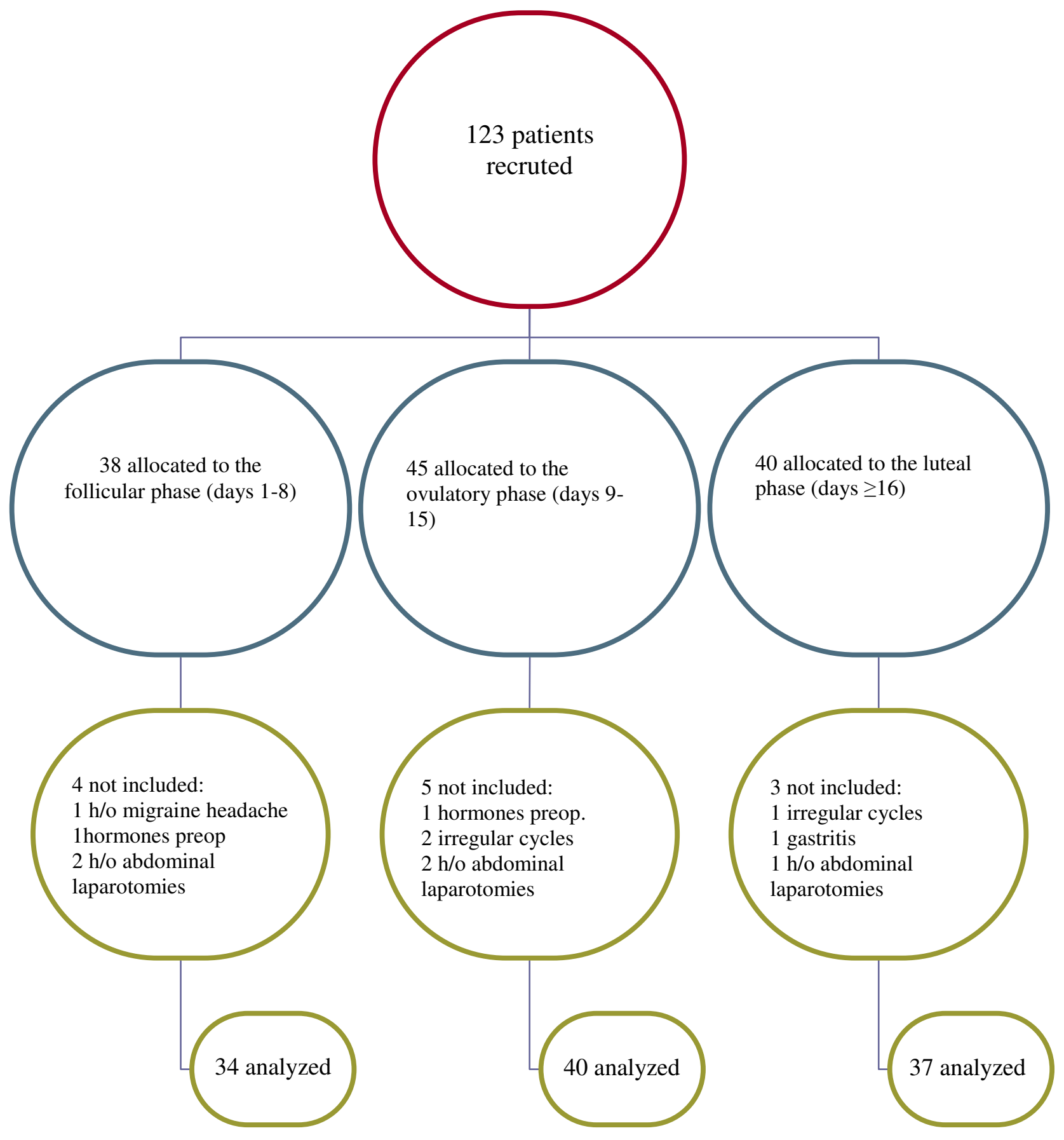

Figure 1. Flow diagram of patients' distribution. 
TABLE 1 Studies about the influence of menstrual phase on the incidence of PONV cited.

\begin{tabular}{|c|c|c|c|c|}
\hline $\begin{array}{l}\text { Reference [Number] } \\
\text { type of study }\end{array}$ & $\begin{array}{l}\text { Type of anesthesia/ } \\
\text { surgery }\end{array}$ & $\begin{array}{l}\text { PONV } \\
\text { prophylaxis }\end{array}$ & $\begin{array}{l}\text { Groups [Menstrual cycle days] } \\
\text { ( N ) }\end{array}$ & $\begin{array}{l}\text { Outcomes anc } \\
\text { PONV incidel }\end{array}$ \\
\hline $\begin{array}{l}\text { Eberhart et al., } \\
\text { 2000.[7] } \\
\text { Systematic review }\end{array}$ & $\begin{array}{l}\text { general or regional, different } \\
\text { techniques/ mixed surgery }\end{array}$ & $\begin{array}{l}\text { yes }=1468 \\
\text { no }=1157\end{array}$ & $\begin{array}{l}(\mathrm{N}=2625) \\
{[1-7]} \\
{[8-12]} \\
{[13-15]} \\
{[16-24]} \\
{[25-\text { end of cycle }]}\end{array}$ & $\begin{array}{l}\text { PONV at least } \\
40.4 \% \\
32.9 \% \\
38.1 \% \\
34.5 \% \\
41.5 \% \\
\end{array}$ \\
\hline $\begin{array}{l}\text { Beattie et al., } \\
\text { 1993. [9] } \\
\text { Prospective }\end{array}$ & $\begin{array}{l}\text { general, standardized } \\
\text { /gynecologic laparoscopy }\end{array}$ & $\begin{array}{l}\text { yes }=74 \\
\text { no }=26\end{array}$ & $\begin{array}{l}{[1-8](\mathrm{N}=35)} \\
{[9-28](\mathrm{N}=65)}\end{array}$ & $\begin{array}{l}\text { PONV 24h } \\
\mathbf{7 1 . 4 \%} \\
46.2 \%\end{array}$ \\
\hline $\begin{array}{l}\text { Beattie et al., } \\
\text { 1991. [10] } \\
\text { Retrospective }\end{array}$ & $\begin{array}{l}\text { general, standardized } \\
\text { /gynecologic laparoscopy }\end{array}$ & $\begin{array}{l}\text { yes }=77 \\
\text { no }=158\end{array}$ & $\begin{array}{l}(\mathrm{N}=235) \\
{[1-8]} \\
{[9-\text {-end of cycle] }}\end{array}$ & $\begin{array}{l}\text { PONV 24h } \\
\mathbf{5 1 . 6 \%} \\
21.6 \%\end{array}$ \\
\hline $\begin{array}{l}\text { Möllhoff et al., } 1995 . \\
\text { [11] } \\
\text { Prospective }\end{array}$ & $\begin{array}{l}\text { general, two anesthesia } \\
\text { techniques/gynecologic } \\
\text { laparoscopy }\end{array}$ & yes & $\begin{array}{l}{[1-8](\mathrm{N}=41)} \\
{[9-16](\mathrm{N}=57)} \\
{[17-28](\mathrm{N}=52)}\end{array}$ & $\begin{array}{l}\text { PONV 24h } \\
\mathbf{2 9 . 3 \%} \\
10.5 \% \\
15.4 \% \\
\end{array}$ \\
\hline $\begin{array}{l}\text { Honkavaara et al., } \\
1991[12] \\
\text { Retrospective }\end{array}$ & $\begin{array}{l}\text { general, three anesthesia } \\
\text { techniques/ } \\
\text { gynecologic laparoscopy }\end{array}$ & no & $\begin{array}{l}{[25-6](\mathrm{N}=11)} \\
{[8-12](\mathrm{N}=22)} \\
{[13-15](\mathrm{N}=22)} \\
{[20-24](\mathrm{N}=13)}\end{array}$ & $\begin{array}{l}\text { PONV 24h } \\
18 \% \\
32 \% \\
54 \% \\
77 \% \\
\end{array}$ \\
\hline $\begin{array}{l}\text { Sener et al., } \\
2005 \text { [13] } \\
\text { Prospective }\end{array}$ & $\begin{array}{l}\text { general, standardized/ } \\
\text { gynecologic laparoscopy }\end{array}$ & no & $\begin{array}{l}{[25-6](\mathrm{N}=10)} \\
{[8-12](\mathrm{N}=12)} \\
{[13-15](\mathrm{N}=10)} \\
{[20-24](\mathrm{N}=16)}\end{array}$ & $\begin{array}{l}\text { PONV at } 2 \mathrm{~h}^{*} \\
\sim 44 \% \\
\sim \mathbf{6 6} \% \\
\sim 27 \% \\
\sim \mathbf{9 5} \%\end{array}$ \\
\hline $\begin{array}{l}\text { Gratz et al., } \\
1996 \text { [14] } \\
\text { Retrospective }\end{array}$ & $\begin{array}{l}\text { Ambulatory gynecologic } \\
\text { laparoscopy and/or } \\
\text { non gynecologic }\end{array}$ & $\begin{array}{l}\text { yes } 668 \\
\text { no } 205\end{array}$ & $\begin{array}{l}\text { no PONV prophylaxis }(\mathrm{N}=205) \\
{[1-8](\mathrm{N}=63)} \\
{[9-16](\mathrm{N}=70)} \\
{[17-28](\mathrm{N}=50)} \\
{[29-35](\mathrm{N}=22)}\end{array}$ & $\begin{array}{l}\text { POV 24h } \\
63 \% \\
61 \% \\
42 \% \\
59 \%\end{array}$ \\
\hline
\end{tabular}

* Estimated numbers because only figures presented 
Table 2. Patients' demographics and intraoperative data.

\begin{tabular}{|c|c|c|c|}
\hline & $\begin{array}{c}F I \\
(n=34)\end{array}$ & $\begin{array}{c}O 2 \\
(n=40)\end{array}$ & $\begin{array}{c}\text { L3 } \\
(n=37)\end{array}$ \\
\hline Day of menstrual cycle & $1-8$ & $9-15$ & $>=16$ \\
\hline $\begin{array}{l}\text { Average length of menstrual } \\
\text { cycles (days) }\end{array}$ & $27.74(1.8)$ & $27.85(0.7)$ & $28.5(1.0)^{* \dagger}$ \\
\hline Age (yr) & $31.6(8.0)$ & $35.6(7.2)$ & $34.8(9.6)$ \\
\hline $\mathrm{BMI}\left(\mathrm{kg} / \mathrm{m}^{2}\right)$ & $21.9(2.5)$ & $23.1(3.4)$ & $22.5(3.6)$ \\
\hline ASA physical status (I/II) & $27 / 7$ & $37 / 3$ & $27 / 10$ \\
\hline $\begin{array}{l}\text { Smoking } \mathrm{n}(\%) \\
\text { History of motion sickness }\end{array}$ & $18(53 \%)$ & $17(43 \%)$ & $20(54 \%)$ \\
\hline and/or PONV n (\%) & $18(53 \%)$ & $15(38 \%)$ & $12(32 \%)$ \\
\hline Duration of anesthesia (min) & $70.26(27.5)$ & $65.4(32.1)$ & $77.8(25.4)^{*}$ \\
\hline $\begin{array}{l}\text { Thiopental (mg) } \\
\text { Type of surgery (n) }\end{array}$ & $322(42.9)$ & $326(44.8)$ & $322(44.5)$ \\
\hline $\begin{array}{l}\text { Ovarian cystectomy / } \\
\text { Tumor resection }\end{array}$ & 19 & 22 & 24 \\
\hline $\begin{array}{l}\text { Myomectomy } \\
\text { Laparoscopic assisted }\end{array}$ & 9 & 9 & 8 \\
\hline vaginal hysterectomy & 0 & 0 & 1 \\
\hline $\begin{array}{l}\text { Procedures for infertility } \\
\text { Risk score for PONV* n }(\%)\end{array}$ & 6 & 9 & 4 \\
\hline 1 & $9(27 \%)$ & $9(23 \%)$ & $12(32 \%)$ \\
\hline
\end{tabular}




\begin{tabular}{l|ccc}
\hline 2 & $12(35 \%)$ & $17(43 \%)$ & $17(46 \%)$ \\
3 & $11(32 \%)$ & $13(33 \%)$ & $8(22 \%)$ \\
4 & $2(6 \%)$ & $1(3 \%)$ & $0(0 \%)$ \\
\hline Average number of risk & $2.18(0.9)$ & $2.15(0.8)$ & $1.89(0.7)$ \\
scores & & & \\
\hline
\end{tabular}

* statistically significant $\mathrm{L} 3$ vs $\mathrm{O} 2, \mathrm{P}<0.05$,

$\dagger$ statistically significant L3 vs F1, P<0.05

Data presented as mean (SD) or $\mathrm{n}(\%)$.

Simplified risk score for PONV by Apfel et al.: female gender, history of motion sickness or PONV, non-smoking, the use of postoperative opioids. None, one, two, three or four risk factors indicate $10 \%, 21 \%, 39 \%, 61 \%$ or $79 \%$ incidence of PONV. 